\title{
Non-representational approaches to the unconscious in the phenomenology of Husserl and Merleau-Ponty
}

\author{
Anastasia Kozyreva ${ }^{1,2}$
}

Published online: 24 December 2016

(C) The Author(s) 2017. This article is published with open access at Springerlink.com

\begin{abstract}
There are two main approaches in the phenomenological understanding of the unconscious. The first explores the intentional theory of the unconscious, while the second develops a non-representational way of understanding consciousness and the unconscious. This paper aims to outline a general theoretical framework for the nonrepresentational approach to the unconscious within the phenomenological tradition. In order to do so, I focus on three relevant theories: Maurice Merleau-Ponty's phenomenology of perception, Thomas Fuchs' phenomenology of body memory, and Edmund Husserl's phenomenology of affectivity. Both Merleau-Ponty and Fuchs understand the unconscious as a "sedimented practical schema" of subjective being in the world. This sedimented unconscious contributes to the way we implicitly interpret reality, fill in the gaps of uncertainty, and invest our social interactions with meaning. Husserl, however, approaches the unconscious in terms of affective non-vivacity, as a sphere of sedimentation and the horizon of the distant past which stays affectively connected to the living present. Drawing on these ideas, I argue that these two accounts can reinforce one another and provide the ground for a phenomenological understanding of the unconscious in terms of the horizontal dimension of subjective experience and a nonrepresentational relation to the past.
\end{abstract}

Keywords The unconscious · Consciousness · Affectivity · Memory · Sedimentation · Past-horizon $\cdot$ Phenomenology

Anastasia Kozyreva

kozyreva.a@gmail.com

1 Center for Adaptive Rationality, Max Planck Institute for Human Development, Berlin, Germany

2 Section for Phenomenological Psychopathology and Psychotherapy, Clinic for General Psychiatry, University Hospital Heidelberg, Heidelberg, Germany 


\section{Introduction: situating the problem of the unconscious}

I can live more things than I can represent to myself, my being is not reduced to what of myself explicitly appears to me (Merleau-Ponty 2012, 310).

The topic of the unconscious spans such various fields as philosophy, cognitive science, theoretical and clinical psychology, notoriously including psychoanalysis where this notion finds its most famous conceptualization and therapeutic application. Even though the unconscious is no longer a scandal for science and philosophy, it still holds strong positions as one of the most challenging topics for the research of the human mind. One of such challenges in particular concerns a conceptual contradiction that the idea of the unconscious mental life presents for our understanding of consciousness. As John Kihlstrom points out, it is not the existence of automatic processes in our body and brain that challenges consciousness, but rather the assumption that mental life itself can be devoid of its conscious character (Kihlstrom 2013). Such an assumption in turn can lead to a hypothesis that conscious awareness is not a necessary characteristic of the mind and that some part of our mental representations - such as for instance thinking, memory, and perception-can take place without phenomenal awareness and influence our behavior without us realizing it. The theoretical question then arises as to how conceive of the possibility for a mental state (e.g., a thought about one's brother, a memory of one's childhood or a seeing of a road sign) to occur in the mental life and not being a conscious thought, an explicit memory or a conscious case of seeing.

This puzzling question has defined, for the large part, the respective relations between phenomenology and psychoanalysis in the course of the last century. ${ }^{1}$ Its formulation can be traced back to Franz Brentano's work, who not accidentally was a teacher of both Edmund Husserl and Sigmund Freud during their studies in Vienna. Brentano famously argues against possibility of unconscious representations claiming that it amounts to the idea of an unconscious consciousness which in turn bears on a serious contradiction. This contradiction, however, is not a contradiction in terms: the idea of an unconscious consciousness, as he puts it, is not the same as a non-red redness (Brentano 1973, 79). The contradiction is rather a contradiction in essence: something analogous to an unconscious representation would be "an unseen seeing," that is such a seeing that does not see. Maurice Merleau-Ponty brings this line of thought even further when he writes that "an unconscious thought would be a thought that does not think" (Merleau-Ponty 2012, 396).

\footnotetext{
${ }^{1}$ Such relations and corresponding theoretical issues have been the subject of several productive investigations. See, for instance, the volume Founding Psychoanalysis Phenomenologically, edited by Dieter Lohmar and Jagna Brudzinska and featuring different approaches to this topic (Lohmar and Brudzinska 2012), as well as a collection of essays Approches phénoménologiques de l'inconscient co-edited by Maria Gyemant and Délia Popa (Gyemant and Popa 2015). Other relevant recent contributions to the topic, such as those by Rudolf Bernet, Aaron Mishara, Dan Zahavi, Thomas Fuchs, Bruce Bégout, Jagna Brudzinska, Nicolas De Warren, and Nicholas Smith, are all to a larger or lesser extent discussed in the present paper.
} 
This argument, developed in Brentano's Psychology from an Empirical Standpoint (Brentano 1874), is directly related to his view on consciousness as inner representation (innere Vorstellung) ${ }^{2}$ which accompanies mental acts, but in such "a peculiarly intimate way" that would not lead to an objectifying, reflexive relation, nor to infinite regress. ${ }^{3}$ As he points out, the term "consciousness" refers to the mental phenomenon insofar as this phenomenon has certain content and can therefore be conceived of as a representation of this content accompanied by the representation of the mental phenomenon itself. This implies that, for Brentano, the inconceivability of an unconscious consciousness ensues from the inconceivability of an internally unperceived representation. It also suggests that only mental phenomena with representational content are necessarily accompanied by inner consciousness. For Brentano, of course, this encompasses the totality of mental states since they all are defined by intrinsic intentionality, i.e., directedness towards their primary objects.

Thus, the central point in understanding the problem of consciousness and correlatively of the unconscious, in this perspective, revolves around the representational nature of conscious phenomena. This perspective has been implicitly adopted in both Freud's and most of Husserl's writings on the matter and shaped the way they approached the issue.

Unlike Brentano, Freud is not threatened by the conceptual contradiction involved in the idea of unconscious representations and instead advocates the possibility of nonconscious mental states which can influence one's conscious life and behavior. As Bernet points out, Freud's aim is to understand "the way in which unconscious representations appear in consciousness without negating their origin in the unconscious" (Bernet 2002, 329). In this sense, Freud, in his attempts to clarify the unconscious, still largely relies on the possibility to conceive of the unconscious representations or, more generally, of the unconscious way of appearing and manifestation. At the same time, Freud is convinced that consciousness has strict boundaries and that it makes no sense to expand any notions of it so that the concept could somehow include all the complexity of the unconscious. Thus, in A Note on the Unconscious in Psychoanalysis, he claims that not only the form of presentation, but also "the laws of unconscious activity differ widely from those of the conscious" (Freud 2008, 39) and that "we have no right to extend the meaning of this word [i.e., conscious] so far as to make it include a consciousness of which its owner himself is not aware" (Freud 2008, 36).

Husserl, on the other hand-especially at the early stages of his thought-agrees with Brentano that there is a contradiction in the idea that the unconscious is opposite to

\footnotetext{
${ }^{2}$ Vorstellung is often translated as either "presentation" or "representation." The latter appears to be more common and adequate and will be preferred here as well. The main reason for this is that the use of the term in its current philosophical meaning was established in Kant's philosophy, who employed it as a German version of the Latin term representatio (Cassin and Rendall 2014, 891). Note, however, that in the English translation of Brentano's Psychology from an Empirical Standpoint the term is translated as "presentation."

${ }^{3}$ In this spirit, he claims: "The presentation (Vorstellung) of the sound and the presentation of the presentation of the sound form a single mental phenomenon; it is only by considering it in its relation to two different objects, one of which is a physical phenomenon and the other a mental phenomenon, that we divide it conceptually into two presentations" (Brentano 1973, 98).
} 
consciousness, while influencing it without subject's awareness. Along these lines, in Logical Investigations, he dismisses the task to account for "obscure, hypothetical events in the soul's unconscious depths" (Husserl 1970, 105). In the Appendix IX to his lectures on time-consciousness, Husserl refutes the idea that there can be any "unconscious" content that subsequently becomes conscious in retention and insists that "consciousness is necessarily consciousness in each of its phases" (Husserl 1991, 123). For Husserl, consciousness encompasses both the sphere of explicit wakeful awareness and the obscure background of conscious life. In this spirit, in the Ideas II, he points out that the sphere of self-consciousness cannot be restricted only to the narrow scope of attentive or alert awareness, but must include in itself equally all "background," obscure conscious experiences (Husserl 1989, 115).

In the Appendix to Husserl's Crisis of European Sciences and Transcendental Phenomenology, written by Eugen Fink, the phenomenological stance regarding the problem of the unconscious finds a somewhat different elaboration. Instead of dismissing the significance of the challenge altogether, Fink states that the problem of the unconscious relies on "a naïve and dogmatic implicit theory about consciousness" that requires systematic reconsideration. This suggests that a phenomenological idea of the unconscious is possible, but should be necessarily based on "an explicit analysis of consciousness" that employs the methodical means of phenomenological philosophy in general and of the intentional analysis in particular (Husserl 1936/ 1970, 387).

Fink's proposal clearly goes in the direction of the intentional theory of the unconscious and supports Husserl's brief remarks in the same text concerning "unconscious" intentionalities (Husserl 1936/1970, 237). The above mentioned appendix was written by Fink in 1936 and is consistent with the general attitude of Husserl's phenomenology towards "depth psychology" and especially towards the critical position the latter assumes in relation to the "consciousness-idealism of phenomenology." Husserl's way to overcome this "naïve and dogmatic" theory of consciousness is related to the transformation of Brentano's idea of inner consciousness into the absolute inner timeconsciousness (Husserl 1991). The resulting conception of consciousness, as Bernet argues, is not at odds with the idea of the unconscious and paves the way to the possible detecting of the "unconscious mode of appearance" in acts of presentification (Vergegenwärtigung). In this regard, consciousness and the unconscious are understood as two different types of representations. Such a position is generally consistent with Fink's indication in the mentioned Appendix that phenomenological analysis of consciousness might contribute to the intentional theory of the unconscious.

This direction in the phenomenological exploration of the unconscious still relies on the theory of the representational structure of consciousness, even if with significant differences from the one advocated by Brentano and implicitly accepted by Freud. However, this is not the only possible way of exploring consciousness and the unconscious phenomenologically. Another way would be to approach this issue in non-representational terms and to question not merely the mode of appearance of the unconscious, but rather its intrinsic immanence to consciousness and subjective experience. This latter perspective explores the complexity of the unconscious that cannot be easily reduced only to a question of manifestation and representation. The most elaborate version of this approach is pursued in the works of Maurice Merleau-Ponty and Thomas Fuchs. Another non-representational approach to the unconscious can be 
found in Husserl's later woks related to genetic phenomenology and passive constitution of subjective experience.

Thus I assume that there are two main directions in the phenomenological understanding of the unconscious: one exploring the intentional theory of the unconscious and the other inquiring into a non-representational way of approaching consciousness and the unconscious respectively.

In the framework of contemporary phenomenology, an example of the first account can be found in Bernet's analysis of the unconscious representations in phantasy. His approach underlines a particular aspect of the issue, namely the manifestation of unconscious representations in the reproductive inner consciousness. According to Bernet's interpretation, the unconscious can be clarified phenomenologically not as "amputated, unperceived consciousness" (Bernet 2002, 330) but as another type of self-consciousness. Such self-consciousness is defined in respect of what appears (the absent, the alien) and how it appears in consciousness (reproductively as opposed to impressionally), but not in terms of this appearance being itself devoid of a certain "conscious" quality or accompanying representation. Jagna Brudzinska's work is also closely related to Bernet's approach. She describes the unconscious as "a phantasmaticimaginary structure of intentionality" and views the unconscious as the manifestation of absence and originary otherness (Brudzinska 2006).

The importance of non-representational approaches to the unconscious has been emphasized by Dan Zahavi in his book Self-Awareness and Alterity. Notably, he claims that when "phenomenology moves beyond an investigation of object-manifestation and act-intentionality, it enters a realm that has traditionally been called the unconscious" (Zahavi 1999, 207). By drawing attention to Husserl's analyses of affectivity and passivity, Zahavi proposes that we see the phenomenological unconscious as a fundamentally altered form of consciousness and a "depth-structure of subjectivity" (Zahavi 1999, 206). Aaron Mishara provides a thorough analysis of this aspect of Husserl's work in the phenomenological clarification of the unconscious in his article "Husserl and Freud: Time, memory and the unconscious" (Mishara 1990). This line of thought is also central to the present article.

Husserl's analyses of passivity and pre-predicative experience have been a major source of inspiration for phenomenological approaches to the unconscious and other closely related phenomena. For instance, in his recent book Towards a Phenomenology of Repression, Nicholas Smith develops a phenomenological model for understanding Freud's concept of the unconscious by focusing on the theory of repression. He also relies heavily on Husserl's analyses of passivity and genetic constitution and paves the way toward understanding repression within the sphere of the living present as "a necessary part of all constitution" (Smith 2010, 305). Another interesting facet of contemporary phenomenological discussion about the unconscious is the topic of dreams and sleep in the works of Nicolas de Warren. In his article "The Inner Night: Towards a Phenomenology of (Dreamless) Sleep," de Warren takes on the challenge that the phenomenon of dreamless sleep presents to our conceptions of consciousness and self-awareness. By exploring this experience that "exists for no one" and venturing into the depths of Husserl's analyses of time-consciousness and passivity, de Warren presents sleep as the way that consciousness constitutes itself as the absence of itself (de Warren 2010). His insightful analyses of the metaphor of sleep contribute to the phenomenological clarification of the past, self-forgetting, and the unconscious. De 
Warren's analyses in fact run parallel to my own attempts to bring together Husserl's and Merleau-Ponty's ideas of sedimentation, past-horizon, and the past existing in the mode of oblivion.

Equally important to the phenomenological clarification of the unconscious is the topic of drives and instincts. In Husserl's approach, drive-intentionality (Triebintentionalität) has quite broad implications that range from analyses of concrete bodily drives to a universal drive-intentionality that generally motivates the protentional openness of the streaming life of subjectivity (Husserl 1973, 595). Drives, as tendencies emerging in obscurity, belong to the sphere of the senses, which Husserl also calls "a hidden reason" (verborgener Vernunft) and which constitutes the precognitive, passive level of subjective experience (Husserl 1989, 277). Non-objectifying drive-intentionality presents an interesting case of a non-representational relation to objects and has direct links to the psychoanalytic perspective, which becomes particularly evident in Husserl's later manuscripts (Husserl 2014). Husserl's deliberations on this topic have attracted a considerable amount of attention in phenomenological literature, some of which draws explicit connections to the issues of repression and drives in Freud's work (Lee 1993; Brudzinska 2004; Smith 2010).

These discussions demonstrate that contemporary phenomenology has no reservations about taking seriously the challenge of the unconscious and that there are several valuable avenues of thought arising out of this topic. In the framework of this paper, I will focus on one of these, namely, the non-representational way of accounting for the unconscious in phenomenology. The idea is to explore not only critical arguments exposing the insufficiency of representational approaches but also to propose a constructive phenomenological account of the non-representational unconscious. As will be shown, such an account can be found in theories which explore how subjectivity is connected to its past life beyond the representational relation constituted by explicit remembering. When it is acknowledged that our experience is not restricted to representational content, it becomes possible to see the unconscious as a horizontal dimension that connects past and present without making this past an explicit object of observation. Such an approach therefore is not restricted to the living present, nor is it focused on unconscious intentionalities. Rather, it explores this particular horizontal "opening upon the past" (Merleau-Ponty 2012, 413) that makes subjective experience meaningful and consistent with itself.

On the one hand, the main advantage of such non-representational approaches consists of breaking with the unfortunate view of the unconscious as a hidden reservoir of past experiences piling up "behind the back" of consciousness, as well as with the contradictory concept of the unconscious consciousness, or "memory that does not remember." On the other hand, phenomenological treatment of such phenomena as sedimentation, forgetting, body memory, and affectivity allows for the preservation of the very idea of the unconscious by approaching it as a horizontal dimension of subjective experience. The results of this approach can arguably be extended to the area of cognitive psychology and its views on the so-called cognitive unconscious and implicit memory.

Accordingly, in what follows I will look into two major examples of nonrepresentational accounts. First, I will present Maurice Merleau-Ponty's and Thomas Fuchs' proposal for an approach to the unconscious as a "sedimented practical schema" of subjective being in the world. Afterwards, I will turn to Husserl's idea of affective 
consciousness and examine another possible non-representational phenomenological account of the unconscious. My argument is that both Husserl's and Merleau-Ponty's accounts of the unconscious can reinforce one another and provide a ground for the phenomenological approach to the unconscious in terms of non-representational relation to the past. In the conclusion, I will situate the non-representational approach to the unconscious in relation to the issue of cognitive unconscious and implicit memory as discussed in cognitive psychology.

\section{Non-representational accounts of the unconscious: Merleau-Ponty and Fuchs on the unconscious and body memory}

The critique of the representationalist approach to consciousness and correspondingly to the unconscious is characteristic of several post-Husserlian phenomenological projects. ${ }^{4}$ Arguably the most fruitful account of non-representational consciousness inside the phenomenological tradition is given by Maurice Merleau-Ponty, who emphasizes the role of embodiment, being in the world, and of intersubjectivity as fundamental constitutive dimensions of subjectivity. He asserts that "there is no private sphere of consciousness" (Merleau-Ponty 2012, 395) and that consciousness is entirely transcendence, "the simultaneous contact with my being and with the being of the world" (Merleau-Ponty 2012, 396). For him, this implies the reevaluation of the very idea of transcendence and of intentionality, which accordingly can be understood not as a cognitive relation to an object by positing it mentally in one's mind, but rather as a concrete embodied and situated directedness towards the world.

In his Phenomenology of Perception, Merleau-Ponty adopts Husserl's notion of "operative" intentionality (fungierende Intentionalität) and interprets it as a prereflective directedness which establishes a natural, pre-predicative unity of our being in the world (Merleau-Ponty 2012, lxxxii). Contrary to act-intentionality, which describes the relation to objects on the level of judgments and reasoning, and thereby constitutes the basis for objective knowledge, operative intentionality can be understood as "the body-subject's concrete, spatial and pre-reflective directedness towards the living world" (Reuter 1999, 72). While bringing the subject's embodiment and the practical nature of bodily directedness to the foreground of the constitutional issue, Merleau-Ponty points to an apparent insufficiency of representational accounts. Such accounts, so his argument goes, fail to make sense of a particular intentionality involved in the performance of movements ${ }^{5}$ and all essentially bodily phenomena. Furthermore, they lead to an altogether false image of subjectivity, featuring it as

\footnotetext{
${ }^{4}$ For example, Bernet underlines that "the development of the analysis of intentionality by Heidegger, Aron Gurwitsch, Sartre, Merleau-Ponty and Michel Henry has been basically nothing other than a putting into question of the representationalist objectivism and the egological subjectivism progressively installed by Husserl at the beginning of this century" (Bernet 1994, 231).

5 "This [accomplishment of a movement] is only possible if consciousness is not defined as the explicit positing of its objects, but rather more generally as a reference to an object that is practical as much as theoretical. That is, if consciousness is defined as being in the world, and if the body in turn is defined not as one object among others, but as the vehicle of being in the world. So long as consciousness is defined through representation, the only possible operation for it is of forming representations" (Merleau-Ponty 2012, 525).
} 
consisting of distinct representations which are either available or unavailable to conscious awareness.

Merleau-Ponty highlights two main problems in understanding consciousness and the unconscious in representational terms. The first problem, which he ascribes to the philosophies of consciousness, consists in the impossibility to conceive of any content of experience beyond the "manifest content spread out in distinct representations" (Merleau-Ponty 2012, 171). The second problem, belonging to the theories of the unconscious, "is to double this manifest content with a latent content, also made up of representation" (Merleau-Ponty 2012, 171). He uses an example of sexuality to make a point that featuring it in terms of either conscious or unconscious representations does not come any closer to understanding its continuous presence "in human life as an atmosphere" (Merleau-Ponty 2012, 171).

Merleau-Ponty's critique of the approach to consciousness and the unconscious as consisting of representations is directly related to his idea that subjective experience cannot be made transparent to itself, but is instead intrinsically characterized by its selfopacity and fundamental ambiguity. In this case, Merleau-Ponty clearly diverges from Cartesian as well as Husserlian ideal of certainty and their belief that self-consciousness provides us with a perfect vantage point towards inner workings of our minds. Instead, he draws on the idea of bodily structure of perception, where the body is both what perceives and what stays invisible for itself: "it [the body] is neither tangible nor visible insofar as it is what sees and touches" (Merleau-Ponty 2012, 94). The ambiguity of bodily experience and the non-representational character of bodily awareness and perception lie at the foundation of Merleau-Ponty's view of subjectivity and inspire his descriptions of various phenomena. Contrary to representational approaches that feature contents of conscious experience through what appears to the subject, MerleauPonty believes that what we acquire through experience is not represented in our minds in either conscious or unconscious way. ${ }^{6}$ He claims that we can live more things than we can represent to ourselves and that our experience is by no means restricted to the content of intentional representations (Merleau-Ponty 2012, 310).

Thus Merleau-Ponty makes a radical suggestion for the phenomenological theory of the unconscious - to avoid talking about conscious vs. unconscious representations altogether, and rather understand the unconscious as a "sedimented practical schema" (Merleau-Ponty 2010, 191) and as our own self-opacity. In a similar vein, in the Phenomenology of Perception, he gives examples of situated feelings and actions, which are defined as much by their directedness to objects as by their ambiguity and obscurity regarding their own contextuality: "We would be equally wrong by making sexuality crystallize in 'unconscious representations' or by setting up in the depths of the dreamer a consciousness that can identify sexuality by name. Similarly, love cannot be given a name by the lover who lives it. It is not a thing that one could outline and designate, it is not the same love spoken of in books and newspapers, because it is rather the way the lover establishes his relations with the world; it is an existential signification. The criminal does not see his crime, nor the traitor his betrayal, but not because these exist deep within him as unconscious representations or tendencies, but rather because these crimes or betrayals are so many relatively closed worlds and so

\footnotetext{
${ }^{6}$ On the non-representational account of learning and skill acquisition see Hubert Dreyfus' paper Intelligence without representation - Merleau-Ponty's critique of mental representation (Dreyfus 2002).
} 
many situations. If we are situated, then we are surrounded and cannot be transparent to ourselves, and thus our contact with ourselves must only be accomplished in ambiguity" (Merleau-Ponty 2012, 401) - my emphasis. Here we can see that such ambiguity and self-opacity refer not merely to impossibility of complete selfknowledge but rather to what Merleau-Ponty calls "situatedness" of subjective experience. In other words, we are intransparent to ourselves because our experience is not restricted to representational content and thereby cannot be made an explicit object of observation.

Along the same lines, in his lecture courses on Institution and Passivity and Visible and Invisible, Merleau-Ponty presents the unconscious as "perceptual consciousness,"7 drifting not that far from the definition of the unconscious in terms of the intrinsic selfopacity of conscious experience. Already in Husserl, perception is described as an unending process, in which objects appear only to a certain degree of approximation and never in fullness (Husserl 2001). For Merleau-Ponty, it means that perceptual consciousness relies on unconscious syntheses which complete our otherwise fragmentary view of reality by means of particular subjective predispositions and a sedimented history. The unconscious can be therefore understood as a background against which we see objects, not as something that can be grasped in our representations of these objects: "This unconscious is to be sought not at the bottom of ourselves, behind the back of our 'consciousness,' but in front of us, as articulations of our field. It is 'unconscious' by the fact that it is not an object, but it is that through which objects are possible, it is the constellation wherein our future is read-It is between them as the interval of the trees between the trees, or as their common level. It is the Urgemeinschaftung of our intentional life, the Ineinander of the others in us and of us in them" (Merleau-Ponty 1968, 180).

The description of the unconscious as the "interval between the trees" appears to be quite a precise analogy: the unconscious is literally taken to be the way we fill in the gaps of uncertainty in objects' perception - and what is more - a way which determines how exactly we will relate to them. Different people will fill up the gaps between these metaphorical trees quite differently: depending on their background and individual history, someone might see a situation as threatening, while someone else might see an equivalent situation as promising and exciting. It is an interesting feature of our experience that when a certain amount of information is missing (which is the case for any kind of inadequate or essentially incomplete experience, such as perception and interaction with other people), we tend to fill it in with our expectations based on previous experiences. Even if we see objects only from a certain perspective and never from all possible angles, our perception still functions as if it were complete.

Thus, when Merleau-Ponty claims that "perception is unconsciousness" (MerleauPonty 1968, 189), he intends to emphasize not what one directly perceives as an object as being unconsciousness, but that perception functions as a medium through which objects are perceived in this or that manner. He states that uconsciousness "is and is not perceived. For one perceives only figures upon levels - and one perceives them only by relation to the level, which therefore is unperceived" (Ibid). Such a definition of the

\footnotetext{
7 "These descriptions [i.e., of oneric consciousness] mean that the unconscious is a perceptual consciousness, it proceeds like perceptual consciousness by means of a logic of implication and promiscuity, it gradually follows a path whose total slope it does not know [...]" (Merleau-Ponty 2010, 208).
} 
unconscious as a perceptual consciousness however does not imply that Merleau-Ponty ever intended to reject the distinction between consciousness and the unconscious altogether. He rather sought to avoid understanding the unconscious in terms of another psychic reality or some kind of other "I think," which forms representations "behind the back" of the conscious subject (Merleau-Ponty 2010, 207). Instead of the strictly dualistic idea separating conscious and unconscious processing, Merleau-Ponty develops the idea that the unconscious is a necessary part of any conscious experience. The unconscious thus is not the opposite of consciousness, it is "the very perceptual consciousness in its ambiguity, opacity, multiplicity of meanings, and unending quest for interpretation" (Stawarska 2008, 62).

A similar critique of representationalism regarding consciousness and the unconscious returns in Merleau-Ponty's accounts of memory in his lecture course on Institution and Passivity. In this course, the problem of memory oscillates between two modes of our relation to the past: memory as "construction" and memory as "conservation" of the past. In the first mode, roughly corresponding to that of explicit memory, the past is constituted as an object of one's recollections. This is a transcendent past which gets to be constantly recreated in the history of subjective transformations. It is a "construction" as long as it becomes the past which I can remember and bring to my present awareness and link it actively to other events in my life. This is not the past which merely happened, but rather the past as it is remembered. As to the second mode, Merleau-Ponty first calls it "conservation" of the past, only to subsequently criticize this formulation as it relies on the idea of memory-traces or representations residing in some kind of reservoir or collector of past experiences. Refuting this idea, Merleau-Ponty nevertheless claims that there is the past for us, which exists not in the mode of remembering but in the mode of oblivion. ${ }^{8}$

Once again, the very idea of representation proves to be the main enemy obstructing the comprehension of subjective relations with the past, which makes the past either a mere construction of one's memory or a mere collection of memory-traces. MerleauPonty thinks that the truth lies in between these two modes of past-relation and can only be articulated when the idea of representation regarding memory is abandoned altogether. He claims that memory should not be seen as an opposite of forgetting but that it could be elucidated through our relation with a past on the pre-reflective level of embodied existence (Merleau-Ponty 2010, 208-209).

To summarize, there are several important steps clarifying Merleau-Ponty's approach to psychoanalysis and to the problem of the unconscious. First of all, unlike Husserl, Merleau-Ponty's phenomenology finds itself confronted with the same challenge which was central to the psychoanalytic endeavor and which concerns the issue of consciousness being intransparent to itself and defined as much by its explicit as by its implicit or latent dimensions. As he puts it: "Phenomenology and psychoanalysis are not parallel; much better, they are aiming toward the same latency" (Merleau-Ponty 1993, 71). Secondly, Merleau-Ponty believed that the idea of representation obscures the understanding of both consciousness and the unconscious. He aims to overcome this limitation in his theory of operative intentionality, embodiment, and perceptive consciousness. In the perspective opened by these ideas, he features the unconscious as a sedimented practical schema and as the subject's ambiguity with regard to his own

8 “Le passé existe dans le mode de l'oubli” (Merleau-Ponty 2003, 272). 
situatedness in the world. And finally, he applies his critique of representationalism to the phenomenon of memory and suggests that the subject's relation to the past is mediated by forgetting as much as by remembering.

These last two directions in understanding the unconscious (via situated, embodied, perceptive consciousness and via non-representational relations to the past) remain very close to each other within Merleau-Ponty's thought. The necessary step to bring them together has been accomplished by Thomas Fuchs' phenomenology of body memory, one of the aims of which is to bring to the fore the basic temporal structure of embodied existence. By analyzing the phenomenon of implicit memory, Fuchs shows that it consists in a different kind of presence of the past than that of the explicit memory. While explicit recollection presumes the presentification of one's past experiences in a personal autobiographic memory, implicit memory, for its part, cannot be clarified via any kind of representational relation. As embodied subjects we cannot be said to have the past as an object, but rather we are ourselves this past (Fuchs 2000, 76). This past becomes a modus of one's bodily existence and stays unnoticed but effective, unseen but present through bodily dispositions, familiarities, habits, unintentional avoidances and omissions.

Body memory serves as a foundation for our personal identity - such an identity which exists beyond explicit memory and narratives we tell about our lives, but instead constitutes the indispensable basis for our self-familiarity. It is personal inasmuch as it accumulates experiences and dispositions specific for each particular individual.

The unconscious character of body memory once again is not due to any incarnation of an implicit core of subjectivity behind the back of consciousness in the form of either subconscious psychic or else automatic brain processes. Similar to Merleau-Ponty's views, Fuchs understands the unconscious not in terms of representations or hidden intentionalities but as a sum of bodily dispositions which tacitly define the individual relation to the world and to other people. For instance, a shy person does not need to form representations either consciously or unconsciously, in which her attitude would find its manifestation. Instead, as Fuchs remarks, such a person would exhibit her attitude in her very posture or tone of the voice, in her avoidance to assert herself firmly in front of other people or to risk expressing her opinions in public. In the same vein, in Merleau-Ponty's example, love is described not as relation to a person which could be grasped in a particular object-directed intentionality, but rather as "an existential signification," as a "way the lover establishes his relations with the world" (Merleau-Ponty 2012, 401).

Another example can be found in the phenomenon of traumatic experience, which contributes to the phenomenological clarification of the dynamic unconscious. The repressed trauma does not survive as some kind of representation, objective "trace" or "image," which cannot be erased. Instead, it survives "only as a style of being and only to a certain degree of generality" (Merleau-Ponty 2012, 85). As Fuchs points out, the influence of past traumatic experiences on a traumatized person manifests itself in resistance and defensive behavior (not necessarily transparent for the person) in situations triggering such unconscious dispositions (Fuchs 2012a, 98). The unconscious influence of traumatic experiences persists not in the form of explicit menacing objects, but as a medium 
making these objects appear as threatening. The dynamic unconscious is therefore not understood as a reservoir for repressed feelings, thoughts or desires, but as transformations of the lived body and the lived space, which restructure one's field of experience and determine against which background one would see and judge new existential situations and interactions with other people.

By extending the life of consciousness beyond the narrow focus of self-knowledge and present awareness, by bringing the experiencing subject back into the intersubjectively shared world and into the concreteness of its embodied and affective being, the phenomenology of the lived body overcomes the idea of the unconscious as hidden "behind the back" of consciousness, and takes it as the practical schema of our bodily being in the world and as the structure of our field of perception. Summarizing this position, Fuchs writes: "[The unconscious] surrounds and permeates conscious life, just as in picture puzzles the figure hidden in the background surrounds the foreground, and just as the lived body conceals itself while functioning. It is an unconscious which is not located in the vertical dimension of the psyche but rather in the horizontal dimension of lived space, most of all lodging in the intercorporeality of dealings with others, as the hidden reverse side of day-to-day living" (Fuchs 2012a, 100).

While Bernet claims that the unconscious is the presence of the absent, appearance of the non-appearing, Fuchs develops Merleau-Ponty's opposing view that the unconscious is "absence in presence, the unperceived in the perceived" (Fuchs 2012a, 101). This absence however is not the concealed or isolated reverse side of consciousness, but rather its own way of being - the sum of incorporated predispositions, habits and the like, which themselves do not appear in any graspable way, but instead constitute a background against which we relate to the world.

\section{A non-representational account of the affective unconscious in Husserl's Analyses Concerning Passive Synthesis}

Husserl's own most consistent attempt to provide an account of the unconscious hinges upon the level of pre-predicative experience and passive constitution. Similarly to the previously discussed phenomenological approaches, for Husserl the unconscious is also the problem of consciousness. He decides, however, to work on it against the background of the idea of affectivity and associative syntheses, and not starting from the idea of cogito or intentional representation. A sketch of the phenomenological theory of the unconscious can be found in Husserl's Analyses concerning Passive Synthesis and later manuscripts, which are now published in the volume 42 of Husserliana: Grenzprobleme der Phänomenologie: Analysen des Unbewusstseins und der Instinkte, Metaphysik, späte Ethik: Texte aus dem Nachlass (1908-1937).

In my view, there are three important aspects of the affective unconscious in Husserl that should be made explicit here. The first concerns its formal definition in terms of Grenzphänomen which designates the unconscious as the zero-level of affective vivacity and features it as relative to the graduality of consciousness. The second corresponds to the idea of the affective past-horizon and the unconscious as "sedimented." The third explores the topic of the affective conflict and Husserl's take on the issue of repression. Inquiry into these three aspects of the unconscious in Husserl's genetic phenomenology will allow us to see that not only Merleau-Ponty's but also Husserl's phenomenology 
can contribute to understanding consciousness and the unconscious in the nonrepresentational way. ${ }^{9}$

\subsection{Zero-point of affective vitality and the unconscious as Grenzphänomen}

The first and the most basic sense of the unconscious for Husserl is the non-vivacity as opposed to different degrees of vivacity of consciousness. In the Analyses, Husserl employs several metaphors to describe this phenomenon. Some of them, as Aaron Mishara illustrates (Mishara 1990, 36), evoke images from the German Romantic literary tradition, such as those of the "nightfall" or the "night of the unconscious." Nicolas de Warren underlines Husserl's employment of wakefulness and sleep as metaphors for transformations of time-consciousness, where de-presentification in retention and loss of "intuitivity" are seen as analogous to "falling asleep" (de Warren 2010). Other terms are also used by Husserl to feature the unconscious as the underworld and the realm of death. Closely related to these metaphors are the archeological images of sedimentation. ${ }^{10}$ Other expressions play with the psychological and even psychophysical vocabulary of the time and situate Husserl's notion of the unconscious at the threshold of affective intensity. The difference between conscious and unconscious is grasped in terms of foreground/background differentiations and in reference to affective power and powerlessness (Kraftlosigkeit). Mathematical vocabulary provided Husserl with another useful term for the unconscious as the zero level of vivacity and an "affective zero-horizon" (affektiver Nullhorizont) (Husserl 2001, 216/ 167).

What brings these different metaphors and analogies together is an attempt to situate the unconscious at the border of the affective vivacity of consciousness. Such a border, however, is not something that exists objectively, which could be measured or determined in quantitative terms. Moreover, Husserl does not need to suggest any functional relation between the intensity of conscious representations and the intensity of physical phenomena, since from the start he attributes intensity or vivacity to consciousness itself and not to its content. In this spirit, he writes: "[The unconscious] designates the nil of this vivacity of consciousness and, as will be shown, is in no way a nothing: A nothing only with respect to affective force and therefore with respect to those accomplishments that presuppose precisely a positively valued affectivity (above the zero-point). It is thus not a matter of a "zero" like a nil in the intensity of qualitative moments, e.g., in intensity of sound, since by this we mean that the sound has ceased altogether (Husserl 2001, 216).

The unconscious in Husserl is clearly a concept founded on the idea of affective graduality of consciousness and designates the zero-level of affective vivacity. However, the unconscious in this sense is by no means an opposite of consciousness, but is

\footnotetext{
${ }^{9}$ An important aspect of this topic, namely the one that concerns drives and instincts, will as such be absent from the current interpretation. However, it is essential to Husserl's analyses of association and affectivity and thereby makes up part of what I designate here as the affective unconscious.

${ }^{10}$ All those metaphors get mixed in Husserl's descriptions, as for instance : “... every accomplishment of sense or of the object becomes sedimented in the realm of the dead, or rather, dormant horizontal sphere, precisely in the manner of a fixed order of sedimentation: While at the head, the living process receives new, original life, at the feet, everything that is, as it were, in the final acquisition of the retentional synthesis becomes steadily sedimented" (Husserl 2001, 227) - my emphasis.
} 
necessarily relative to it. It should be noticed that this formulation makes of the unconscious a Grenzphänomen and does not contribute to the substantial definition of the phenomenon. However, based on this general definition, Husserl succeeds - if not in fully developing a phenomenological account of the unconscious - at least in sketching several directions of its possible elaboration.

According to Mishara, there are two different types of the unconscious which can be separated here: the pre-affective unconscious in the impressional sphere of consciousness and the unconscious as the sphere of forgetfulness and the remote past (Mishara 1990). In Husserl, this distinction can be found in Appendix 22 to $\S 35$ of the Analyses (Husserl 2001, 525). The pre-affective unconscious mostly designates all the multiplicity of affective tendencies which do not reach the ego's awareness and thereby stay in the background against which prominent tendencies come to be differentiated. In my view, this sense of the unconscious as pre-affective should rather be called preconscious and distinguished from the proper unconscious which refers to the pasthorizon. In what follows, I will restrict my analyses to the unconscious in this latter sense. This terminological choice finds its support in Husserl's later differentiation between the sphere of the affective past-horizon and of "sedimentation," on the one hand, and the pre-affective background, on the other hand. The term "unconscious" is then reserved for the sedimented: "there are no other unconscious backgrounds than those of sedimentation" (Husserl 2014, 37). Thus, in order to understand Husserl's idea of the unconscious in this sense, we need to focus on the three following notions: background consciousness, past-horizon, and sedimentation. These clarifications will allow to go beyond merely formal definition of the unconscious as Grenzphenomen and to make explicit the important link between the problem of the unconscious and the problem of memory.

\subsection{Affective past-horizon and the unconscious as "sedimented"}

The past is a real stumbling block for any theory of memory which seeks not only to explain processes of retention and remembering but equally to understand how the past experience can be preserved so that it can be brought back to awareness. Merleau-Ponty pinpoints a certain paradox here, consisting in the fact that any idea of past-preservation already presumes that this past should be present in some peculiar way (Merleau-Ponty 2012, 436). Husserl successfully deals with this paradox in the case of retention which serves the double purpose of being past in the present and preservation of this present at the same time. The same goes for remembering which by definition is a presentification of the past. Only the remote past, the sphere of forgetfulness and sedimentation, appears to have this status of inexplicable absence: it is nowhere to be found, it does not appear in any way, and yet it must be somehow preserved since it affects our present life implicitly and can be reawakened in the explicit memory.

It is almost impossible to avoid this paradox within the frame of the temporal analytics of consciousness since this paradox itself belongs to the temporal order. As long as one approaches the problem of the past exclusively in terms of its temporal distance, the past becomes necessarily transcendent to the present life of consciousness. However, as already argued in the previous section of the paper, the presence of the remote past and its effectiveness in nearly any domain of one's present life can be approached without necessarily conceiving of it in terms of hidden representations, but 
rather as an implicit dimension incorporated in one's way of being. Both MerleauPonty and Fuchs appeal to this dimension in terms of one's personal history as sedimented in the living body and the way it inhabits its space. Husserl also developed an idea of sedimentation and the remote past which served the purpose to solve the mentioned paradox and to explain how the "sphere of forgetfulness" can remain connected with the present life of consciousness.

In order to do so, Husserl speaks of the constitution of the past in terms of horizon, which makes the inclusion of the past in the sphere of living present possible only in its potentiality and not in its actuality. This potentiality of the past-horizon is made possible due to the retentional structure of consciousness as well as due to the fact that near retention belongs to the impressional present which serves as a source of all affective force. The past-horizon is further divided into spheres of close past, as the near horizon of living retention, and the horizon of the distant past or " "the forgotten' that carries on the differentiated retentional path of the past" (Husserl 2001, 529). This retentional path is carried on into an indeterminate empty horizon, that Husserl describes as "dead horizon," "endless past," "sphere of forgetfulness" and finally as the unconscious (Husserl 2001, 513-525). ${ }^{11}$

The horizon of the distant past presents a serious problem for the idea of temporal continuity of consciousness because it presumes the extension of the retentional process beyond the point where this process itself is finished. ${ }^{12}$ An important aspect of Husserl's solution to this issue consists in considering this remote past-horizon not exclusively in terms of its temporal constitution but as an "affective horizon," - that is as constituted essentially through modifications of the affective vivacity of consciousness. Importantly, in the Analyses, retention means not only temporal modification but designates equally the loss of affective vivacity. The past-horizon, accordingly, is described as a horizon of affective gradations, which extends from its peak in the impressional present to the less and less affective retentional past until it reaches the point of ineffectiveness.

\footnotetext{
${ }^{11}$ Similarly, in her analyses on retention in Husserl, Lanei Rodemeyer distinguishes between "near" and "far" retention (Rodemeyer 2006, 88-91). Whereas the former is involved in the constitution of the living present, the latter designates what is here called the distant past-horizon. In my work, I prefer maintaining this distinction in terms of retention and "past-horizon" (instead of distinguishing between near and far retention) for several reasons. First, this terminological choice allows to overcome all possible confusion between "near" and "far" types of retention, while preserving the sense of retention for the continuous temporal modification of the living present into the just-past. Secondly, it allows to clearly preserve Husserl's own difficulties regarding the extent of the retentional process. For him, retention presupposes, in the first place, a "connection to the immediate realm of the present" (Husserl 2001, 416), whereas the distant "submerged" past exceeds the process of retentional modification. Husserl underlines that the retentional process stops at some point and gets transformed into the sphere of sedimented unconscious. This sedimented distant past constitutes the core of the past-horizon. Finally, the use of the term "past-horizon" instead of "far retention" allows to overcome the merely temporal aspects of the constitution of the past. The term "past-horizon," therefore, is conceptually more suggestive and allows accounting for not merely temporal, but also "unconscious" and affective aspects of the distant past, as well as underlying its horizontal connectedness with the present.

${ }^{12}$ In this spirit, Husserl points out that the unconscious as sedimented past history goes beyond temporal modifications: "The past is finished time (erledigte Zeit), the finished duration [...]" (Husserl 2001, 520). He further asserts that the retentional process ceases and sinks into the atemporal unconscious: "Earlier I thought that this retentional streaming and the constitution of the past would continue to go on incessantly even within complete obscurity. But now it seems to me that one can dispense with this hypothesis. The process itself ceases. [...] this retentional modification leads further and further into the one nil" (Husserl 2001, 226).
} 
The retentional modification, as Husserl underlines repeatedly, is a transformation of consciousness itself, consisting of changing modes of temporal appearances as well as in the affective depleting of the original impressions. In this regard, de Warren points out that retentional consciousness not only " 'de-presentifies' its intentional object but also 'de-presentifies' itself” (de Warren 2010, 283). By this he means that becoming unconscious is inherent to conscious self-transformation. However, the retentional process is not only depleting and "clouding over," but it is equally a process of identification, inasmuch as it is the conservation of noematic senses of objects: "And when there is no affection coming from the diverse objects, then these diverse objects have slipped into sheer nightfall, in a special sense, they have slipped into the unconscious" (Husserl 2001, 221). This "nightfall," however, is not nothing: all noematic senses are preserved there, but in such a peculiar and undifferentiated manner that prevents them from reaching conscious awareness.

Thus, on the one hand, the retentional process is a process of identification securing the sameness of objective senses. On the other hand, it is a process of affective depleting and temporal modification. It means that an objective sense's temporal mode changes, loses its affective impact on the impressional present and yet the sense itself is not altered in these transformations. A song heard yesterday is still the same song, even if it no longer belongs to one's actual field of experience: "In the fading away, the tone itself thus does not lose anything that it originally was; if it is given at the end as completely empty of differences with respect to content, then this concerns its mode of givenness, not it itself" (Husserl 2001, 220). Such a transformation of the mode of givenness consists in a shift "from an explicit sense to an implicit sense" (Husserl 2001, 223). Moreover, empty presentations themselves cannot be described in terms of representational or explicit intentionality. The object-directedness in the past is therefore grasped as "implicit intentionality" (Husserl 2001, 222), which can be reawakened and brought back to intuitive presentification, but which as such is in no way an actual objectifying intention.

Now, an important question needs to be answered on how this affectively depleted and temporally distant past can be reawakened again. Husserl claims that the unconscious past-horizon is a necessary condition for affective awakening and the latter is a prerequisite for remembering: "Awakening is possible because the constituted sense is actually implied in background-consciousness, in the non-living form that is called here unconsciousness" (Husserl 2001, 228). In the process of awakening of the distant past, an affectively discharged, sedimented sense "emerges" from out of the "fog" and "what is implicit becomes explicit once more" (Husserl 2001, 223-224). Such an awakening is a product of affective communication ${ }^{13}$ and therefore a product of associative synthesis.

Affective awakening of the past and remembering are two closely related phenomena, which, however, should not be identified. While the first is essentially a phenomenon of affective nature, by means of which a past sense regains its affective force, the latter is an act of intuitive presentification, in which a sense becomes the object of an explicit intention. "The affective awakening," — as Husserl remarks — "does not bring

\footnotetext{
13 “Affective communication would mean that every contribution of affective force by any 'member' of something connected in distance through homogeneity and prominence augments the force of all its "comrades'” (Husserl 2001, 224).
} 
the uniform sense to intuition [...], but does indeed effect an un-uncovering" (Husserl 2001, 225). Not all affectively awakened senses become actual intuitions or recollections, most of them never reach this level. In this sense, remembering is the transition of an awakened empty presentation in reproductive intuition. Without this awakening no remembering would be ever possible.

Thus remembering is a modification of the mode of givenness of an objective sense and thereby of consciousness itself, and so is the retention: the latter changes the impressional consciousness into an undifferentiated past-horizon, the former transforms it into reproductive consciousness of the past. Bernet claims that such a reproductive consciousness itself can be understood as unconscious representation. However, in Husserl, the unconscious does not correspond to reproduction, but rather to the undifferentiated consciousness of the past-horizon. Moreover, I think it is consistent to claim that this consciousness is by no means a representational or an intentional one, but is an affective consciousness of the indistinct horizon of the past, which Husserl also calls background-consciousness: "One may well say that within the zero-stage, all special affections have passed over into a general indifferentiated affection; all special consciousnesses have passed over into one, general, persistently available backgroundconsciousness of our past, the consciousness of the completely unarticulated, completely indistinct horizon of the past, which brings to a close the living, moving retentional past" (Husserl 2001, 220).

In this sense, the past and all its content is preserved as a "horizon," temporally and affectively relative to the impressional consciousness. Accordingly, the preliminary conclusion can be drawn that there are two main modes of our relation to the past: the remembered past, in which it becomes an object of explicit recollection, and the affective past, which is present as an affective horizon and as a sphere of sedimentation and forgetfulness. In this latter perspective, the past has no other reality which could be attributed to it besides affective reality, relative to one's impressional present. In the Analyses as well as in later manuscripts, Husserl clarifies it as a sphere of unconscious sedimentation (Sedimentierung), whose affective status is always dependent on the actual impressional experience.

The idea of the unconscious as the past-horizon constituted through affective and temporal modifications is closely linked to the idea of its ineffectiveness. If, as Husserl insists, "positive affective force is the fundamental condition of all life" (Husserl 2001, 219 ), and if the affective vivacity of the unconscious is close to zero, then its affective impact must be fully dependent on the conditions of the present subjective experience. And indeed, this seems to be exactly what Husserl implies claiming that the affective reinforcement for the awakening of past senses must always come from the living present, as well as from dispositions and motivations inherent to it.

Although this position is arguably justified as it comes to the general conditions of affectivity (if the living present is completely empty and lifeless no communication with the past is possible), it nevertheless causes some trouble regarding the affective status of the past itself. Moreover, the reality of our subjective experience may cast some doubts on Husserl's view. The riddle of the past asserts its importance not because it has lost its impact on our present life but precisely because it has not. There are past experiences, which however temporally distant remain constantly affectively present to us, even if their influence as such remains unnoticed. Also, the distinction between the sedimented, as characteristic of the distant past, and the totality of non-sedimented, as 
characteristic of the living present (Husserl 2014, 37), might appear contradictory. There is indeed a level of implicit and sedimented experience which by no means can be called unconscious as ineffective and dead for us. In what follows, I shall investigate the possibility to account for this issue within Husserl's own approach. Notably, it is in these deliberations concerning repression and affective conflict that Husserl comes closer than ever to drawing some explicit connections between the psychoanalytical and phenomenological approaches to the unconscious.

\subsection{Affective conflict and the unconscious as repressed}

One of the radical differences between Freud's and Husserl's theories of the unconscious concerns the affective status of the past and its capacity to affect the present. While for Husserl the unconscious corresponds to the zero level of affective intensity, it is the affective capacity of the unconscious which plays the major role for Freud. The main reason for taking the unconscious as ineffective and incapable of exercising any influence on the present consciousness lies in the very idea which specifies the unconscious as a frontier and the final point of modification and vitality.

However, Husserl also outlined other directions of enquiry concerning the affective status of the remote past and the sphere of forgetfulness. Already in the Appendix 19 to the Analyses, he questions the possible development of affections as "progressing" or "rousing from the unconscious" (Husserl 2001, 518-519). In order to understand this line of thought, it is fruitful to address Husserl's take on the issue of affective suppression.

First of all, in the Analyses, Husserl approaches suppression of affective tendencies as a function of contrast. In general, contrast delineates the affective relation between opposite or antagonistic tendencies. The highest form of contrast is affective conflict: "Contrast is the affective unification of opposites [...] Rivalry, conflict, is the dissension of opposite things" (Husserl 2001, 514). The applications of the principle of contrast are quite broad. On the one hand, association of contrast can lead to the increase of affective intensity of affectively unified opposite terms. Husserl's examples include the augmentation of the vivacity of the whole (a string of lights, a melody) by means of contrast between parts, so that a louder tone makes a softer one more noticeable, or a sudden change in brightness of a particular light influences the noticeability of the whole string. On the other hand, contrast in the form of affective conflict can lead to the suppression of concurrent affections, especially if they are not integrally cohesive (Husserl 2001, 514). Interestingly, such suppression can equally result in an increase of affective vivacity which in this case is confined to the unconscious: "In this case, a special repression takes place, a repression of elements, which were previously in conflict, into the 'unconscious,' but not into the integrally cohesive sphere of the distant past; by contrast, in the living conflict, repression takes place as a suppression, as a suppression into non-intuitiveness, but not into nonvivacity - on the contrary, the vivacity gets augmented in the conflict, as analogous to other contrasts" (Husserl 2001, 514-515).

To a certain extent, the concurrence of affective tendencies which Husserl describes as pertaining to the affective relief of the living present is already a case of suppression and affective conflict: stronger affective tendencies win over their weaker counterparts and suppress them into the background. Moreover, any retentional modification also 
presupposes suppression of other affections which gradually lose their affective impact. However, as it can be seen in the above cited quote, Husserl also has something more specific in mind. Affective conflict suppresses the affective tendencies in the unconscious, but in such a way that the affective vivacity of these tendencies increase instead of diminish. In this case, affection which is "winning out does not annihilate the other ones, but suppresses them" (Husserl 2001, 518) and this suppression has a reverse effect on vivacity of contrasted affections. In this passage, Husserl underlines that repressed elements sink into the unconscious. However, this is not the unconscious in the sense of cohesive, undifferentiated past that has lost its affective impact. Husserl's version of the "repressed" unconscious is alive and has its own affectivity which even imply that affections can evolve or progress from it.

Whether Husserl ultimately meant to separate these two versions of the unconscious - as undifferentiated past-horizon and as repressed - cannot be elucidated on the basis of his texts. Nevertheless, the fact that he was aware of the challenge that repression presents to the phenomenological theory of the unconscious is clear. Not accidental in this sense is the way he approaches it, seeing the repressed unconscious more as an open question than a solution: "Affections can play to each other's advantage here, but they can also disturb one another. An affection, like that of extreme contrast ('unbearable pain') can suppress all other affections, or most of them [...] - this can mean to reduce to an affective zero - but is there not also a suppression of the affection in which the affection is repressed or covered over, but is still present, and is that not constantly in question here?" (Husserl 2001, 518). ${ }^{14}$

It was clear to Husserl that repressed affections do not lose their affective vivacity and can even evolve from the unconscious. Not accidentally, he sees the question of repressed affects as one closely related to Freud's psychoanalysis. ${ }^{15}$ In Husserl's opinion, the phenomenological clarification of instinctual drives and repressed affections can contribute to the eidetic (as opposed to merely subjective) analyses of the unconscious which were first brought to light by the psychoanalytic approach (Husserl 2014, 126).

Bégout, who first linked these fragments from Husserl's later manuscripts to the question of affective efficacy of the past, believes that this might prove that Husserl's view on the affectivity of the past is not uniform. He writes in this regard: "In fact, Husserl develops the decisive idea according to which the repressed affections do not loose, contrary to what one might have thought, their affective validity and effectiveness. Indeed, repression of an affection by another affection privileged by the self, does not nullify its affective force" (Bégout 2000, 187-188) - my translation.

Bégout suggests distinguishing between on the one hand the retentional process, which corresponds to the constitution of the distant past as devoid of affective force, and on the other hand the process of repression, which also leads to non-intuitivity of the past but maintains affective vivacity of the repressed tendencies (Bégout 2000,

\footnotetext{
${ }^{14}$ A similar line of thought returns in the later manuscripts (1934), in which Husserl comes to thematize another kind of affective conflict - the one that belongs to the sphere of drives (Triebe) and affects (Affekte). In the Appendix XIV entitled "Eingeklemmter Affekt," he notes that the intensity of desire is increased not only in an actual turning of one's attention towards the object of such desire but also in the opposite case, when one's desire is ignored and repressed (Husserl 2014, 112).

${ }^{15}$ When he claims, for instance: "Alles Verdeckte, jede verdeckte Geltung fungiert mit assoziativer und apperzeptiver Tiefe, was die Freud'sche Methode ermöglicht und voraussetzt” (Husserl 2014, 113).
} 
216). In a similar vein, when Smith addresses the topic of the repressed unconscious in Husserl's work, he also underlines this double destiny of affective modification in retention. Notably, he shows how Husserl's analysis of the perseverance of sedimented experiences, especially in the sphere of drives and feelings, contributes to understanding the repressed unconscious through the lens of genetic phenomenology (Smith 2010, 228-241).

The phenomenon of repression illustrates that the past cannot be reduced only to temporally modified and obscure experience. Quite the contrary, seeing the past from the perspective opened up by analyses of affectivity allows accounting for essential differences in the way that it maintains connections to the living present. In this sense, it is plausible to accept the zero-affectivity of the past-horizon and repressed affectivity as two main types of affective modification, both of which contribute to the phenomenological understanding of the unconscious.

To summarize, there are several important points clarifying conception of the unconscious that emerges from Husserl analyses of passive synthesis. First, Husserl approaches the unconscious not in terms of cognitive or intentional structure, but as a phenomenon belonging to the affective order of subjective constitution. Husserl's idea of affectivity as constitutive dimension of subjectivity paves the way to seeing consciousness and the unconscious not as mutually exclusive phenomena but as different levels on the scale of affective intensity. Secondly, Husserl develops his understanding of the affective unconscious as the sphere of sedimented past, horizontally connected to the living present. Concept of the affective past-horizon designates a particular mode of givenness of the past and intends to account for the connectedness between the present and the past life of consciousness which exists beyond the level of explicit memory and underlies the possibility of retroactive affective awakening. Finally, Husserl's inquiries into the topic of affective conflict and the issue of repression allow enriching his idea of affective modification and thereby contribute to a phenomenological clarification of the affective vivacity of the past.

\section{Discussion and conclusion: the unconscious as a non-representational relation to the past}

The aim of this paper has been to present an alternative to intentional or representational analyses of the unconscious. By systematically exploring the views of MerleauPonty, Fuchs and later Husserl, I intended to outline a general theoretical framework for the non-representational approach to the unconscious within the phenomenological tradition. One of the main goals of such an approach is to counter the understanding of the unconscious mental life in terms of mental acts or representations of essentially the same type as conscious mental acts but devoid of any conscious quality. Instead of trying to account for unconscious intentionalities, the authors featured in this paper paved the way to quite a different idea of the unconscious.

We have seen that Merleau-Ponty and Fuchs understand the unconscious as a "sedimented practical schema" of subjective being in the world, which contributes to the ways by which we implicitly interpret reality, fill in the gaps of uncertainty, and invest our social interactions with meaning. Husserl's genetic phenomenology reveals another non-representational approach to the unconscious, namely the one based on the 
broadened idea of consciousness and its affective graduality. The most important contribution of Husserl's account of the unconscious concerns his ideas of sedimentation and the affective past-horizon. Significantly, both Merleau-Ponty's and Husserl's conceptions of the unconscious converge on the concepts of sedimentation and horizontal openness of subjective experience upon the distant past. These conceptions, however, allow for quite different concrete interpretations of the unconscious: While Merleau-Ponty and Fuchs explore the bodily dimension of the sedimented unconscious, Husserl ventures into a constitutive problematic and accounts for those "blind" rules and operations that govern the pre-cognitive life of subjectivity and contribute to the continuous interconnectedness of the sedimented past and the living present.

However, when it comes to Husserl's approach to the unconscious, it should be noted that representational phenomena regarding the past are by no means dismissed by him. As we have seen, he attributes to the unconscious a peculiar form of "empty presentation," devoid of affective vitality. Distinct from non-objectifying intentionality of awakened affections, as well as from explicit intentionality of recollections, "empty presentations" must be yet another kind of implicit intention. In these, Husserl asserts, the identical senses must be preserved in an implicit form without any actual intention taking place. ${ }^{16}$

In Merleau-Ponty's terms, one could say that the idea of the past as preservation of memory "traces" is not completely alien to Husserl's thought. There is still some vagueness in Husserl's idea of the past: On the one hand, he conceives of it as horizontal and constituted through temporal and affective modifications while remaining connected to the present and containing the intrinsic possibility of awakening. On the other hand, the status of empty presentations, in which objective senses are preserved in the unconscious, is far from clear. I believe that at this point MerleauPonty's critique of representational intentionality of the unconscious is justified and should complement Husserl's idea of the affective past-constitution. If our present is directed towards the past in the horizontal manner, ${ }^{17}$ this should not imply that the past is preserved in the form of unconscious, empty presentations. Merleau-Ponty's idea is that the unconscious and the past should be thought of not as sedimented in any representational way but rather as sedimented in the very structure of one's personality and behavior, in the way one perceives and interprets the world.

Although I have stressed that representational approaches to the unconscious are characteristic of early psychological and philosophical theories such as those of Brentano, Freud, and early Husserl, it is important to note that understanding the unconscious in terms of hidden mental representations is by no means absent from contemporary research. For instance, Kihlstrom's influential conception of the cognitive or psychological unconscious still largely relies on the idea of unconscious representations. Kihlstrom distinguishes between two different uses of the term

\footnotetext{
${ }^{16}$ As Bégout shows, such an idea might even undermine Husserl's fundamental definition of intentionality in terms of noetic-noematic structure. Namely, he asks how can an objective sense be conceived beyond its mode of givenness, and how, consequently, is it possible that a noematic sense can be preserved beyond any affective or active intention? (Bégout 2000, 204).

${ }^{17}$ The horizontal structure of subjective experience is not limited to the so-called "horizontal intentionalities," which contribute to the adumbrational givenness of perceptual objects. Horizontality equally applies to expectations and to past-experience, meaning that the living present is always open towards not only its future but also its past.
} 
"unconscious." The first refers to automatic mental processes, which themselves have nothing to do with consciousness, but which generate mental content that is essentially available for conscious awareness (Kihlstrom 1987). This category encompasses, for instance, processes involved in calculating distances between objects, or the use of certain phonological and linguistic principles in speech. Even if such unconscious calculations are indispensable for perception, performance of movements, and use of language, they do not need to resemble our conscious computation, estimation, or spatial perception. Kihlstrom suggests distinguishing these automatic unconscious processes from the psychological unconscious that describes mental acts that occur without phenomenal awareness or voluntary control, but that still bear an influence on conscious experience. To this category belong phenomena of subliminal perception, implicit memory, learning, and thinking (Kihlstrom 1990). Unlike automatic processes, this latter type of the psychological unconscious conceptually resembles our conscious experience. It becomes especially clear when implicit perception, memory, and thinking are defined by means of an analogy with conscious representations. For instance, Kihlstrom and his co-authors Jennifer Dorfman and Victor Shames define implicit thought in terms of "activated mental representations of current and past experience [that] can influence experience, thought, and action even though they are inaccessible to conscious awareness" (Dorfman et al. 1996). ${ }^{18}$

A similar situation occurs in research on the implicit memory that makes up part of the psychological unconscious. In cognitive psychology, the definition of implicit memory as distinct from explicit memory usually calls upon conscious awareness. For example, in Daniel Schacter, we find the following definition: "Explicit memory is roughly equivalent to 'memory with consciousness' or 'memory with awareness.' Implicit memory, on the other hand, refers to situations in which previous experiences facilitate performance on tests that do not require intentional or deliberate remembering" (Schacter 1989, 356). In other words, implicit memory designates situations in which "people are influenced by a past experience without any awareness that they are remembering" (Schacter 1996, 161). An operational definition of the phenomenon is then reduced to a presence of retention or response in absence and/or independent of explicit recollection. In experimental conditions, this means that implicit recall is shown to be independent of the explicit memory performance. This general definition allows for including within the group of implicit memory such phenomena as procedural memory of bodily skills, priming on both perceptual and conceptual levels, and emotional memory without recall. ${ }^{19}$ Simple recognition is excluded from the category of implicit memory, as it cannot be shown to be independent of explicit recollection. For the same reason, other phenomena-such as emotional and traumatic memory - fall into the grey area between implicit and explicit cognition.

From the phenomenological point of view, "remembering without awareness" or even an "unconscious retrieval" is an ambiguous definition. At first glance, it may suggest that a subject remembers in the usual fashion, but simply shows no sign of awareness. This can mean that conceptually implicit memory is the same type of intentional experience as explicit recollection except that it is unconscious. In other

\footnotetext{
${ }^{18}$ See also: (Kihlstrom 1990).

${ }^{19}$ For review see: (Schacter et al. 1993; Schacter 1987; Roediger 1990; Shimamura 1986; Kihlstrom et al. 2000).
} 
words, when one sees unconscious processes as analogous to conscious representations, there is a danger of supposing that there is some actual thinking or remembering going on behind the spotlight of phenomenal awareness.

The core of the phenomenological argument consists of pointing out the apparent paradox contained in understanding the psychological unconscious as "seeing that does not see," "thinking that does not think," or "memory that does not remember." In this spirit, Zavahi argues that the unconscious cannot be understood as an ordinary intentional act devoid of self-awareness. He goes on to assert that the unconscious, in its proper sense, should instead be identified with "a quite different depth-structure of subjectivity" (Zahavi 1999, 206). This depth-structure, as we have seen, is to be found not on the level of act-intentionality but rather in a dimension of "opaque passivity which makes up the foundation of our self-aware experience" (Zahavi 1999, 210).

The non-representational accounts of the unconscious discussed here take this line of thought even further. Specifically, they clearly show that a proper understanding of the unconscious cannot limit discussions of memory to its representational or explicit form and at the same time demand an understanding that both connects the past and present life of consciousness on an immanent level and grasps the affective, nonrepresentational presence of the past. In the phenomenology of the lived body, this non-representational relation is further understood as essentially a bodily one. On these grounds, implicit memory is clarified as body memory and includes different types of memory that could not be ascribed to it based solely on the psychological definition of this phenomenon. More specifically, implicit memory is identified as encompassing habitual bodily skills, situational memory, and traumatic and intercorporeal memory, as well as involuntary memories and pre-thematic recognitions (Casey 1987; Fuchs 2012b; Summa 2014).

It has been argued that Husserl's investigations on affectivity and his conception of the unconscious can be taken as another possible explication of this nonrepresentational past-relation. For instance, the phenomenon of affective awakening of the past discussed in section 3.2 may prove useful for phenomenological clarification of implicit remembering. From this perspective, the latter can be understood not in terms of unconscious representations but in terms of implicit or non-objectifying intentionality of affective awakening. As the affective conditions of retroactive awakening precede those of active recollections, they can be preserved even when the explicit memory functions decline. In this case, one's past can continue influencing one's present through affective awakenings that simply never reach the level of intuitive recollections.

Another contribution of phenomenology to the topic of implicit memory is the development of a constructive approach to forgetting. In Husserl, forgetting is seen as a function of affective modification in retention. What is forgotten does not disappear but becomes a part of the implicit background of subjective experience. This past is not presentified, nor is it given to any consciousness. Its mode of givenness is that of an indistinct horizon, a "dimension of escape and absence" (Merleau-Ponty 2012, 436). For Merleau-Ponty, such a view of the unconscious allows for attention to be brought to the dimension of our past experience that inevitably escapes objective thought and exists in the mode of oblivion. In Institution and Passivity, he clearly underlines this fundamental ambiguity: We have to be able to think of the past beyond representation, that is, beyond the past as construction or as preservation (Merleau-Ponty 2010, 208). 
There must be, as he says, another way in which we relate to our past, and yet such another way is constantly missing, most likely because this dimension of the past inevitably escapes objective thought. He expresses this idea in Phenomenology of Perception: "Existence always takes up its past, either by accepting or by refusing it. We are, as Proust said, perched upon a pyramid of the past, and if we fail to see it, that is because we are obsessed with objective thought. We believe that our past, for ourselves, reduces to the explicit memories that we can contemplate. We cut our existence off from the past itself, and we only allow our existence to seize upon the present traces of this past. But how would these traces be recognized as traces of the past if we did not otherwise have a direct opening upon this past?" (Merleau-Ponty 2012, 413).

From this viewpoint, it becomes evident that an important part of memory actually belongs not solely to what emerges on the surface of our affective consciousness but equally to what stays in the background. A person who once fell in love, learned how to read, heard a lion's roar, understood Bayes' theorem, or experienced a car accident will always remain affected by these experiences even if they are not constantly reactualized in his or her memory. Clearly, not all of these events will necessarily have an equal impact on that person's life: some will become fundamental and define his or her personality, others will become acquired skills or habits, some will be reawakened only when similar situations are encountered, and a significant portion of them will probably simply sink into the undifferentiated background. The past remains: not as hidden senses or traces in some deep repository of the mind, but rather in the way these events shape and change one's experience and thereby prefigure the totality of one's attitudes towards the present and the future. Similar to the horizontal structure of perception, in which an object is always approached from different sides while still maintaining a quasi-complete way of appearing, the unconscious past-horizon is what enables the present itself to be experienced in a way that has a meaning within, and is coherent with, the whole of one's experience.

Acknowledgements Open access funding provided by Max Planck Society. I would also like to thank Thomas Fuchs, Lanei Rodemeyer, Mike Finn and the two anonymous reviewers for their valuable comments and suggestions which helped improving this paper.

Open Access This article is distributed under the terms of the Creative Commons Attribution 4.0 International License (http://creativecommons.org/licenses/by/4.0/), which permits unrestricted use, distribution, and reproduction in any medium, provided you give appropriate credit to the original author(s) and the source, provide a link to the Creative Commons license, and indicate if changes were made.

\section{References}

Bégout, B. (2000). La généalogie de la logique : Husserl, l'antéprédicatif et le catégorial. Paris: Libr. philosophique J. Vrin.

Bernet, R. (1994). An intentionality without subject or object? Man and World, 27(3), 231-255.

Bernet, R. (2002). Unconscious consciousness in husserl and freud. Phenomenology and the Cognitive Sciences, 1(3), 327-351.

Brentano, F. (1874). Psychologie vom empirischen Standpunkt. Leipzig: Duncker \& Humblot.

Brentano, F. (1973). Psychology from an Empirical Standpoint. London: Routledge and Kegan Paul; Humanities Press. 
Brudzinska, J. (2004). Assoziation, Imaginäres, Trieb. Köln: Phänomenologische Untersuchungen zur Subjektivitätsgenesis bei Husserl und Freud. Universität zu Köln.

Brudzinska, J. (2006). Die phänomenologische Erfahrung und die Frage nach dem Unbewussten. Überlegungen im Anschluss an Husserl und Freud. In Interdisziplinäre perspektiven der phänomenologie (pp. 54-71): Springer.

Casey, E. S. (1987). Remembering: A Phenomenological Study (Studies in Phenomenology and Existential Philosophy Series). Bloomington: Indiana University Press.

Cassin, B., \& Rendall, S. (Eds.). (2014). Dictionary of Untranslatables: A Philosophical Lexicon. Princeton: Princeton University Press.

de Warren, N. (2010). The inner night: towards a phenomenology of (Dreamless) sleep. In On Time-New Contributions to the Husserlian Phenomenology of Time (pp. 273-294): Springer.

Dorfman, J., Shames, V. A., \& Kihlstrom, J. F. (1996). Intuition, incubation, and insight: Implicit cognition in problem solving. Implicit cognition, 257-296.

Dreyfus, H. L. (2002). Intelligence without representation-merleau-ponty's critique of mental representation: the relevance of phenomenology to scientific explanation. Phenomenology and the Cognitive Sciences, 1(4), 367-383.

Freud, S. (2008). General Psychological Theory: Papers on Metapsychology. New York: Touchstone.

Fuchs, T. (2000). Das Gedächtnis des Leibes. Phänomenologischen Forschungen (5), 71-89.

Fuchs, T. (2012). Body memory and the unconscious. In D. Lohmar, \& J. Brudzinska (Eds.), Founding Psychoanalysis Phenomenologically (Vol. 199, pp. 69-82, Phaenomenologica): Springer Netherlands.

Fuchs, T. (2012). The phenomenology of body memory. In S. C. Koch, T. Fuchs, M. Summa, \& C. Müller (Eds.), Body memory, metaphor and movement (Vol. 84, pp. 9-22). Amsterdam; Philadelphia: John Benjamins Publishing Company.

Gyemant, M., \& Popa, D. (2015). Approches phénoménologiques de l'inconscient (Vol. 110): Georg Olms Verlag.

Husserl, E. (1936/1970). The Crisis of European Sciences and Transcendental Phenomenology. An Introduction to Phenomenological Philosophy (D. Carr, Trans.). Evanston: Northwestern University Press.

Husserl, E. (1970). Logical Investigations. Volume II. J. N. Findlay, Trans. London: Routledge.

Husserl, E. (1973). Zur Phänomenologie der Intersubjektivität. Texte aus dem Nachlaß. Dritte Teil: 19291935 (Vol. XV, Husserliana). Den Haag: M. Nijhoff.

Husserl, E. (1989). Ideas Pertaining to a Pure Phenomenology and to a Phenomenological Philosophy. Second Book: Studies in the Phenomenology of Constitution (R. Rojcewicz, \& A. Schuwer, Trans.). Dordrecht: Kluwer Academic Publishers.

Husserl, E. (1991). On the Phenomenology of the Consciousness of Internal Time (1893-1917) (J. B. Brough, Trans.). Dordrecht: Kluwer Academic Publishers.

Husserl, E. (2001). Analyses Concerning Passive and Active Synthesis: Lectures on Transcendental logic (A. J. Steinbock, Trans.). Dordrecht: Kluwer Academic Publishers.

Husserl, E. (2014). Grenzprobleme der Phänomenologie. Analysen des Unbewusstseins und der Instinkte, Metaphysik, späte Ethik. Texte aus dem Nachlass (1908-1937) (Vol. XLII, Husserliana): Springer.

Kihlstrom, J. F. (1987). The cognitive unconscious. Science, 237(4821), 1445-1452.

Kihlstrom, J. F. (1990). The psychological unconscious. Handbook of personality. Theory and research, 424 442.

Kihlstrom, J. F. (2013). Unconscious processes. In D. Reisberg (Ed.), The Oxford handbook of cognitive psychology: Oxford University Press.

Kihlstrom, J. F., Mulvaney, S., Tobias, B. A., \& Tobis, I. P. (2000). The Emotional Unconscious. Cognition and emotion, 30-86.

Lee, N.-I. (1993). Edmund Husserls Phänomenologie der Instinkte (Vol. 128): Springer.

Lohmar, D., \& Brudzinska, J. (Eds.). (2012). Founding psychoanalysis phenomenologically: phenomenological theory of subjectivity and the psychoanalytic experience (Phaenomenologica, Vol. 199). Springer. doi:10.1007/978-94-007-1848-7.

Merleau-Ponty, M. (1968). The Visible and the Invisible (A. Lingis, Trans.). Evanston: Northwestern University Press.

Merleau-Ponty, M. (1993). Phenomenology and Psychoanalysis: Preface to Hesnard's L'Oeuvre de Freud. In K. Hoeller (Ed.), Merleau-Ponty and Psychology (pp. 67-72). New Jersey: Humanities Press.

Merleau-Ponty, M. (2003). L'institution, la passivité : notes de cours au Collège de France (1954-1955). Paris: Belin.

Merleau-Ponty, M. (2010). Institution and Passivity: Course Notes from the Collège de France (1954-1955). Evanston: Ill.: Northwestern University Press. 
Merleau-Ponty, M. (2012). Phenomenology of Perception (D. A. Landes, Trans.). London: Routledge.

Mishara, A. L. (1990). Husserl and freud: time, memory and the unconscious. Husserl Studies, 7(1), $29-58$.

Reuter, M. (1999). Merleau-ponty's notion of pre-reflective intentionality. Synthese, 118(1), 69-88.

Rodemeyer, L. M. (2006). Intersubjective Temporality. It's About Time. Dordrecht: Springer.

Roediger, H. L. (1990). Implicit memory. American Psychologist, 45(9), 1043-1056.

Schacter, D. (1987). Implicit memory: history and current status. Journal of Experimental Psychology: Learning, Memory, and Cognition, 13(3), 501-518.

Schacter, D. (1989). On the relation between memory and consciousness: dissociable interactions and conscious experience. In H. L. Roediger III, \& F. I. M. Craik (Eds.), Varieties of memory and consciousness: Essays in honour of Endel Tulving (pp. 355-389).

Schacter, D. (1996). Searching for Memory: The Brain, the Mind, and the Past. New York: BasicBooks.

Schacter, D., Chiu, C. Y., \& Ochsner, K. N. (1993). Implicit memory: a selective review. Annual review of neuroscience, 16, 159-182.

Shimamura, A. P. (1986). Priming effects of amnesia: evidence for a dissociable memory function. The Quarterly Journal of Experimental Psychology. A, Human Experimental Psychology, 38(4), 619.

Smith, N. (2010). Towards a phenomenology of repression. A husserlian reply to the freudian challenge.

Stawarska, B. (2008). Merleau-Ponty and Psychoanalysis. In R. Diprose \& J. Reynolds (Eds.), MerleauPonty: Key Concepts (pp. 57-69). Stocksfield: Acumen.

Summa, M. (2014). Spatio-temporal Intertwining: Husserl's Transcendental Aesthetic (Vol. 213, Phaenomenologica): Springer.

Zahavi, D. (1999). Self-awareness and Alterity: A Phenomenological Investigation. Evanston: Ill.: Northwestern University Press. 